\title{
POSITION OF CREATIVE THINKING IN THE ONTOLOGICAL APPROACH TO ARCHITECTURE EDUCATION ${ }^{1}$
}

\author{
Alireza.Ghayoorfar \\ Ph.D student of Architecture, Faculty of Arts and Architecture, Islamic Azad University, Science and \\ Research Branch, Tehran, Iran \\ alireza.ghayoorfar@gmail.com \\ Iraj Etessam \\ Professor of the Faculty of Arts and Architecture, Islamic Azad University, Science and Research \\ Branch, Tehran, Iran \\ ietessam@hotmail.com \\ Seyed Mostafa Mokhtabd \\ Professor of the Faculty of Arts and Architecture, Islamic Azad University, Science and Research \\ Branch, Tehran, Iran \\ mokhtabm@modares.ac.ir
}

\begin{abstract}
Creativity, referred to as innovation, is one of the most important criteria used by architecture experts in the criticism of architecture students' works. In old architecture, spatial benefits, in terms of biological health and the presence of architectures in the environment, has emerged as the first application of space. The priority of presence-existence aspect in the process of current education has turned into a mentality-based innovation from architect-innovator. Here, two thinking creeds try to meet human needs by enhancing existence and modernity with timely happiness criterion. The present study was aimed to refer to the importance of the ontological aspect of behavior in line with human identity, and materialistic innovation in the field of architecture education. The concept of "creativity" in thinking creeds of extremist and knowledge-based doctrines, has formed a theoretical framework for this paper in the edition of the theoretical model into a conceptual model in order to provide a questionnaire, to code, and finally to interpret data. The results of the present study are from two different attitudes of happiness-based experimental innovation, "modernity knowledge extension" against beautiful creativity, human health, traditional extremism showing principle differences, expressing an internal relationship between two criteria, timely inter-dependency and superiority in understanding, taken from modernity attitude in the process of creating works.
\end{abstract}

Keywords: creativity, superiority, happiness, innovation, timely cognition

\section{INTRODUCTION}

The term "architecture" is rooted in humans' age and existence. When examining different eras of human existence, certain similarities, in terms of selecting pictures or concepts, are seen, which are referred to as fashion. Over time, we have been witness to the emergence and fading of paradigms that have occurred based on certain meanings. But no two methods are similar; they are latent and obvious similarities in existential behavior and meaning. What makes them different in terms of essence is time and space. Time shows the emergence and fading of skeletal paradigms based on thinking creeds. The constant efforts to discover realities and reach happiness and transitivity of fashions in modernity creeds are mild and dependent on a different origin. From the difference between the thinking creeds of these two attitudes, we can focus on the root of this attitude distinction in terms of creativity and its application in the process of creation. 


\section{TRADITIONAL CREED: EXISTENCE PERFECTION, INDIVIDUALS' MENTAL HEALTH IN A PUBLIC FRAME}

In tradition, creativity has purpose-related differences, compared to innovations taken from modernity creeds. In order to learn about creativity and ways to reach it, we must compare traditional attitude with its difference from modernity.

By definition, tradition is referred to as a perfect intellect with divine origins, which is introduced by people like prophets, messengers, and avatars (Nasr, 2014, p75).

\section{FOCUSED BEAUTY}

In a thinking creed taken from existence perfection principles, beauty is endowed with creativity in line with existential perfection. In traditional thinking creed, beauty belongs to God, and beautiful faces have meaning and good spirit. But meaningfulness precedes face beauty, as God's creatures precede meaning. In this attitude, unlike what has been introduced in modernity as fashion and happiness, beauty is creation not its purpose. Perfect creation means beauty.

Divine wisdom which is the source and origin of humans' wisdom is both discipline and secret, in other words it is God's beauty. That is why face beauty dominates humans' wisdom taking them away from doubt (Nasr, 2010, p445).

Reasons for humans' origins have been made obvious in different ages. In traditional thinking creed, any natural thing is a reflection of God's power. Nature and objects have divine and spiritual values in addition to their materialistic values. In this creed, natural phenomena are signs of a divine spirit. In this creed, art is a balanced combination. Beauty precedes all other concepts. In artistic works, meaningfulness and spirituality has been emphasized. By definition, in addition to the abovementioned aspects, architecture also requires ontology and worldview; hence, it is more inclusive and more complete than other definitions; and in a traditional viewpoint, it guarantees humans' perfection (Raskin, 1848, according to Akrami, 2002).

In this attitude, architecture is creation; a piece of work which is admirable has been defined. Creation is from God and his beauty. Alaref chapter, verse 31, (Akrami, 2002, p36). In this outlook, beauty is not a purpose. Creation which means perfection guarantees beauty which is not acquired beauty but inherent and original beauty. The identification of this beauty is desired in terms of perfection.

In conclusion, beauty is a prerequisite of reality and existence. Because humans' faces are artistic works, they are themselves artists (Hashr chapter, verse 24). Man is a creature with wisdom, able to create wisdom and beauty. Cognition and aesthetics are qualities which humans have inherited from their God. Creativity is endowed with beauty; hence, not all creations are art, but art is the type of creation which is endowed with beauty (Avani, 1996, p318).

Beauty is a phenomenon which depends upon humans' time and existence, and it is not absolute; based on our existential experiences, what is perceived as beauty today refers to our

Aesthetic cognition. Innovative creatures do not stop in time and in one face in terms of art. The attitude differences between the two creeds are no in terms of change but they are in terms of transformation speed and modification style. Both creeds cause change and modification. Both reach analysis and face paradox from normative intellect. Differences are in criteria and their analysis; when reaching theoretical intellect which based on Feritorf Shwan's attitude is referred to as perfection in traditional attitudes, and creative happiness in modernity creeds. Modernity does not refer to an exact era, but it refers to an era where humans focused on realities not abstract ideas in the field of existential wisdom. Because they relied on realities, they more used epistemology methods than ontology;

Traditional humans like beauty and they create it, even if they do not know that they are creating it. In any traditional civilization, all human qualities are from divine principles (Ganon, 1991; p65). 
Traditional art does not guarantee beauty because it is metaphorical and full of secrets; and creation is more internal and deeper than a simple oral expression. Art is the discovery of reality. In traditional civilizations, arts try to notify humans of reality. Tendency towards perfection, which is rooted in humans' nature (Nasr, 2010; p448).

In humanism, humans by relying on instrumental wisdom try to identify phenomena. Phenomenological self-knowledge is the most important element of humans' wisdom. In romanticism, Kay Perkigard emphasizes the fact that humans are constantly making choices for which humans' minds cannot comprehensively identify phenomena.

Accepting the fact that humans' instincts might be dominated by wisdom is an ancient illusion which has always led humanity to bitter shortcomings throughout history (Reed, 1995; p112).

Feritorf Schwan: "The concepts of art are rooted in the soul, wisdom and mysticism, and divine science not just industrial science. In other words, art inherent principles are typically phenomenal principles of a higher level (Schwan, 1999, according to Nasr, 2010; p18).

\section{INNOVATION; HAPPINESS}

Since paying attention to individuals and empiricism humanism in gaining personal identity questions criterion, and perfection principles of tradition as non-modifiable principles, we must examine and analyze what this experience has brought for humans. In this sense, we focus on modernity in terms of creation.

Modern thinking refers to art as a product of artists' minds, which can only be done by geniuses. Superficiality related to obvious world affairs without considering an artist or genius's mind dimension is not valuable. Art is more complex than humans thought; part of an artist's imaginations and visualizations which have been put into action is a part that has been separated from a routine procedure (Bene Velo, 2001, p285).

In two seemingly different attitudes of modernity and traditional perfectionism, the attitudes of two famous architects have been the focus of attention. Frank Luid Wright, a great modern architect, was asked at age 83: "Which of your works do you like most?" He replied: "The next work," i.e. the next work or the next day in order to learn more about myself. About perfection in architecture, Korbozieh stated that: in architecture, an undeniable event happens when creativity happens. When the mind is trying to provide cohesion and convenience in the structure, it applies more perfect passions by focusing on more simple activities such as the application of usefulness, a passion which comes from poetic forces that are exciting and delighting (Johnson; 1994, p790).

The concept of "travel" is against any stop or pause; the timely meaning of a work is the product of existence and is related to the perfection time of that existence (Sholts, 2002, p48). On the other hand, great architecture masterpieces at the time of Vajed do not have a depreciation dimension. This possesses fixed innate principles, i.e. those eternal principles that guarantee the survival of works; what helps some works to be thought as beautiful for long is more rooted in the meaning of them than their attractiveness. This is what has been claimed by traditional thinking creed.

Modern artists who find themselves able to reconstruct nature and man can become more independent relying on their own creativity. They find themselves to be better, more knowledgeable, being able to apply any kind of construction and creation. Not everybody has this gift. Because it is complex to create objects in modern thinking, it is believed that ordinary people cannot understand or visualize it. An artist's mind is superior to ordinary peoples' minds and only intellectuals and geniuses can comprehend it. They did not limit themselves to a rational system and relied more on their personal deductions; hence, they gradually replaced their intellectual criteria with objective criteria (Pakbaz, 1988; p26).

Creativity, which is referred to as personal enthusiasm, is a factor which cannot be evaluated, i.e. an individual element in art. Whereas the need for beauty which arises from creativity in humans is a natural thing. If special people need interpretations, ordinary people need pictorial art more. In the 
traditional civilization, art communicates with the majority of people. Therefore, in this type of art, there is a deep and meaningful relationship between the face and meaning. In modern art, beauty is an excuse for happiness and creativity (Schwan, 1999, according to Nasr, 2010).

While construction is a boring job, practical architecture is a poetic act which is a metaphor of the universe, expressing a certain type of ontology in order to identify oneself (Alberto Perz Gomez, 1994, according to Akrami, 2003).

Individualistic spirit which is affected by modernity and refers to artists as geniuses, considers artistic works as products of tastes, traditions, and dominant enthusiasms in the society. It is a humanistic and materialistic attitude which arises from modern humanism worldview. If art is an individual act, how are social objectives recognized from social, economic, cultural, and traditional realities of customers?

Traditional art believes beauty to be subject to a perfect purpose trying to manifest a spiritual reality in the frame of humans' perfection; therefore it does not reflect variable happiness. In this thinking creed, in addition to beauty, there is a deep meaning dependent upon an eternal reality. Traditional acts can only be taken from a cognitive, observational, and mystic attitude. And modern innovation based on tradition, and because of personal observation and individual empiricism has no support.

Modern perception of creativity in face beauty dimension has stopped in the excitement of observers' emotions, i.e. a personal-internal understanding which, in a level higher than rational inferences, understands perfect forces in art and architecture; hence. It faces challenges in its beliefs, because belief in perfect and supernatural forces is different from humanism. Hence, because of being Eclipse in the materialistic world and because of relying on disputatious and infinitesimal wisdom, they interpret perfect affairs as poetic forces. (Akrami, 2003, p42).

\section{PERSONAL EXPERIENCE; MODERNITY INNOVATION}

When we make inferences about modern architecture, we must note that this does not only include a set of novel forms, but it is also a novel thinking creed whose results have not been calculated. According to Dante: "What is expressed today might not be something which endures (Bene Velo, according to Pakbaz, 1988, p25).

Modern human, instead of trying to reach the base of realities, claims that he has lowered down reality to his own base. The inconsistency in modernity theories is seen in the inconsistency of ideas and concepts. Modern human does not accept intellect which is cause and sustainable; and it accepts action which is effect and unsustainable. It must be noted that in action, effect is separate from cause, which leads to the unsustainability and transitivity of action. On the contrary, intellect has its fruit in its base (Ganon, 1986, p52).

Novelty and innovation are the disease and prejudice of the present work (Schwan, 1959, p148).

Creating architecture space from the viewpoint of phenomenology on the way of ontology is in fact a novel discipline of the cosmos. Becoming new or the feeling of being new in a construction project is interpreted as a certain type of self-knowledge because human essence is complete with places. In order to have such a feeling, it suffices that today's human does not block his feelings and emotions against miracles less (Alyadeh, 1996; p46).

\section{EXISTENCE PERFECTION}

In order to find an element of discipline in a chaos, we must go beyond factors that have caused such a chaos; to understand this new world, we need to get away from it and stand in a higher level. We need to look at past and compare. This is very difficult due to environmental and intellectual pollutions that have been caused in today's world (Ganon, 1970, p2).

In order to pay attention to creativity in architecture education, what was defined as a framework bringing mental health in Iran's traditional architecture, has been transformed. 
Because today's humans do not feel they belong to their living places, they are considered to be homeless, but they possess novel architecture; structures without existential meaning. The comparison of lifestyles in different eras has been criterion for evaluating humans' existential body tested elements. This is what was tested in humans' lives, not a mentality far from judgement (Higar, 2007, p43).

When criticizing modernity, if spiritual happiness is ignored, we must focus on the short lifespan of humans and the limited mindset of humans. It must be noted that a mental evaluation based on speculations has been used instead of an objective and spiritual evaluation. The results obtained from materialistic inferential intellect must be observed in this statement by Bernard Shaw: "Now we need a number of mad men, and see where we are due to wise people (Shaw, 1950, p83).

Today's art and architecture has been emptied from eternal meaning and beauty; and the meaning of artistic works does not only communicate with perfectionists' clean soul, but we can only hear the meaning of works from their designers and critics. A creative idea has a perfect and eternal origin in any way. All artists whether by relying on consistent traditional principles or depending upon constant modern changes, have rejected the unconsciousness of creation and inspiration. God has invited humans to investigate and discover Garlic internal and external (Faslat chapter, verses 47 through 57). Nature and what includes creation is what has been clearly referred to. Human is included in this constant adaptation. Beauty together with meaning and perfection is related to past eras; with an eternal root, humans belong to their own eras. Norberg Sholts interprets it as the perfection time of humans, and Foeh Long interprets it as intimacy principle. Today's human seeks meaning in his life. Hidgar looks at meaning as a current procedure in time in the viewpoint of phenomenology, but he sees face as variable based on timely principle.

In conclusion, based on the two introduced paradigms and the theoretical framework, creativity and education are considered in the process of architecture education. The goal of beauty arises from eternal creativity and also materialistic innovation in adaptation of humans' mindsets with a beauty and communicating with it. This communication is referred to as a location-existence feel. It is what is considered to be an ultimate concept resulting from beauty-based space-time understanding as the major goal of creativity, whose absence denies humans existence and disturbs mental health. The following conceptual model is about the principles of tradition according to Ganon, Schwan, and Nasr; and about existential experience with innovation according to Sholts and Hidgar's phenomenological comments when recognizing the differences between criteria in two thinking creeds.

Table 1: Criteria of creativity in two paradigms: tradition and modernity 


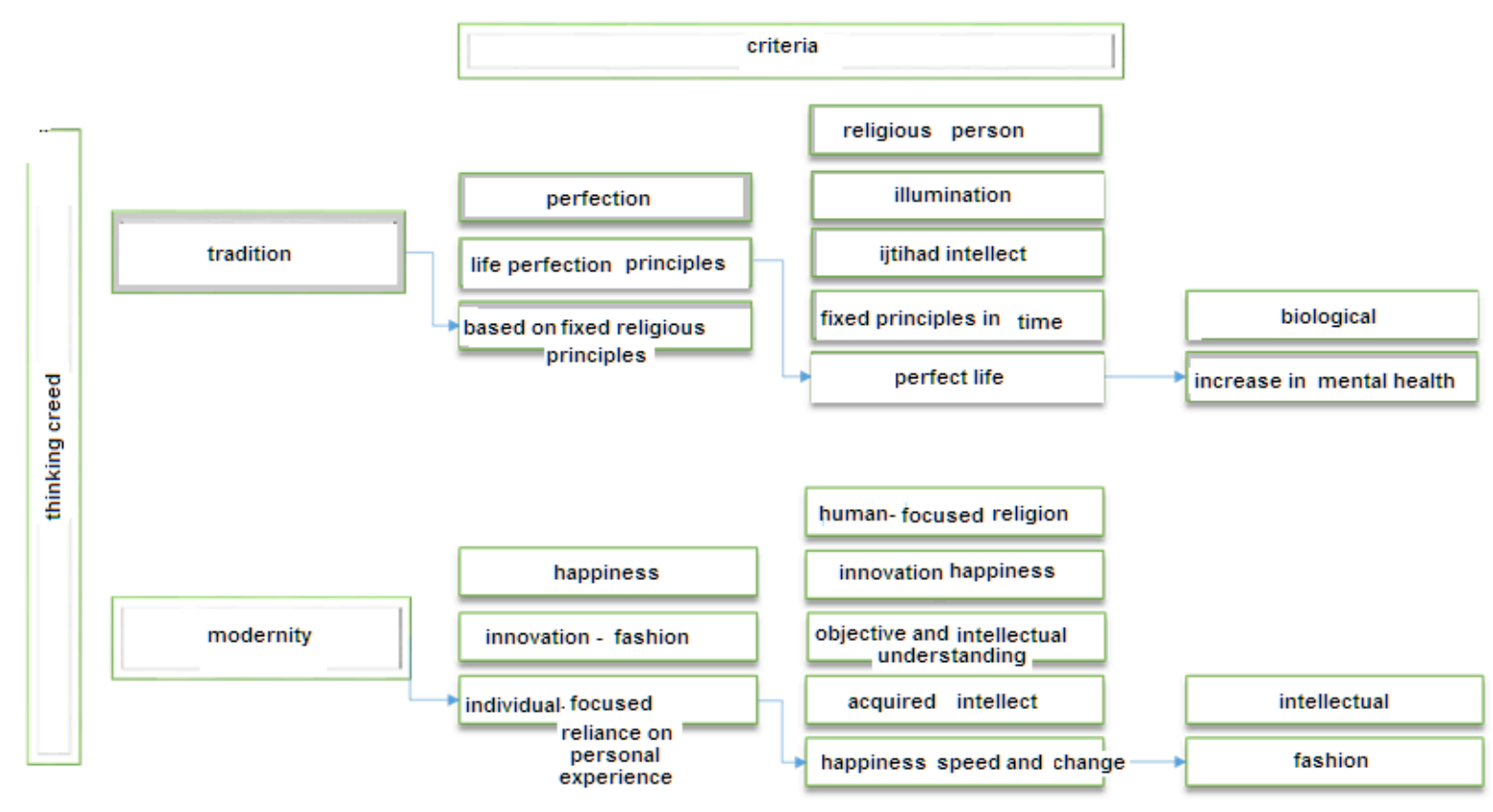

In fact, if we can consider the discovery of location meaning and the mutual relationship of humans' lives when creating meaningful places, in order to provide proper existential behavior, to be the goal of creativity, it will be more necessary to focus on humanistic criteria taken from spatial existence. These factors are recognized in two needs: natural and supernatural. The former is

Life perfection and meaning arising from creation taken from the tradition paradigm, and the latter is timely understanding and communication with the space and time of creation, which is a tangible reality in the modernity paradigm. Since the meaning of location in higher levels of belonging to location is more closely related to individuals, it is dependent upon the style of interpretation and attributing meaning to the created work. According to the principle of inter-dependency, Foeh Long stated that: Understanding of created work is in communication with audiences. The principle of timely understanding received as much attention from the statistical population and architecture educators as life perfection in the conducted study.

\section{RESEARCH METHODOLOGY}

The present research's methodology was selected based on a qualitative research method, using semistructured questionnaire in analysis-based method in order to recognize the relationship between creativity evaluation factors. The collected data in the form of weighable words were classified through coding method and they were analyzed. In order to reach thought bases, samples were divided into two statistical populations, i.e. 1) the group of professors believing in eternal beauty in the creativity of fixed principles of time, 2) and innovation in connection to change and disbelief in fixed eternal principles. Generally, from 47 samples ready to cooperate in order to achieve thinking creeds, samples were divided into two statistical groups; 1) group of experienced professors from fine art universities in Tehran, and 2) amateur teachers in Azad Islamic university. Normally, experienced teachers, using their experiences and existential meanings, focus on creativity in fixed frameworks and in the existential face of space according to work and life history. Younger teachers who use computers engage more in formal humanistic and mindset spaces resulting from events related to the ultra-human processing brain and soft wares that pay less attention to the existential aspect of space; they believe in quick changes and discoveries, but at the same time they consider fixed principles to be not only from a supernatural world or source but also from nature and its discovered and undiscovered principles. Generally, from votes, 47 samples were ready to cooperate with me; and it was tried to determine and classify convergent points. Questionnaire key words were taken from the conceptual model of interviews and library studies. In the edited questionnaire, it has been tried to use 
special meanings in the minds of teachers which were paid attention to in order to express the importance of paying attention to faces of creativity in architecture education. It was also tried to identify criteria for evaluating creativity in the process of producing works by architecture teachers.

The results obtained from the two statistical populations are as follows:

TEACHERS BELIEVING IN ETERNAL PRINCIPLES:

Table 1: Analysis of the results obtained from interviews in the order of audience groups

\begin{tabular}{|c|c|c|c|c|}
\hline Paradigm & criterion & $\begin{array}{c}\text { Experienced } \\
\text { teachers }\end{array}$ & Amateur teachers & total \\
\hline \multirow[t]{3}{*}{ tradition } & $\begin{array}{l}\text { Creativity needing } \\
\text { Eternal principles }\end{array}$ & $29 \%$ & $73 \%$ & $72 \%$ \\
\hline & $\begin{array}{c}\text { Pharaoh } \\
\text { principles }\end{array}$ & $82 \%$ & $53 \%$ & $63 \%$ \\
\hline & $\begin{array}{l}\text { Illumination } \\
\text { principles }\end{array}$ & $70 \%$ & $34 \%$ & $34 \%$ \\
\hline \multirow[t]{5}{*}{ modernity } & $\begin{array}{c}\text { Happiness } \\
\text { (audience motive) }\end{array}$ & $17 \%$ & $82 \%$ & $36 \%$ \\
\hline & $\begin{array}{l}\text { Humanism } \\
\text { experience }\end{array}$ & $68 \%$ & $28 \%$ & $30 \%$ \\
\hline & $\begin{array}{c}\text { Understanding of } \\
\text { objects }\end{array}$ & $29 \%$ & $23 \%$ & $23 \%$ \\
\hline & $\begin{array}{c}\text { Personal } \\
\text { innovation }\end{array}$ & $58 \%$ & 73\% & $68 \%$ \\
\hline & $\begin{array}{c}\text { Beauty timely } \\
\text { perception }\end{array}$ & $52 \%$ & $23 \%$ & $34 \%$ \\
\hline \multirow[t]{3}{*}{ Total } & $\begin{array}{l}\text { Beauty, creativity, } \\
\text { not discriminating } \\
\text { face and meaning }\end{array}$ & $70 \%$ & $30 \%$ & $49 \%$ \\
\hline & $\begin{array}{c}\text { Eternal objective } \\
\text { principles varying } \\
\text { in time- } \\
\text { discoverable }\end{array}$ & $60 \%$ & $82 \%$ & $76 \%$ \\
\hline & $\begin{array}{l}\text { Necessity of } \\
\text { testing mental-life } \\
\text { health }\end{array}$ & $86 \%$ & $78 \%$ & $81 \%$ \\
\hline
\end{tabular}

The examination of the two statistical populations shows that the two groups of experienced and amateur teachers emphasized the constant procedure of recognizing humans from objectives in the form of personal mindsets. In this procedure, experienced teachers have considered creativity to be present in the meaning of innovation, and in the current procedure of education, they have evaluated it based on creative students' ultra-objective and intellectual criteria; but they have evaluated the traditional principles of creativity based on eternal, ultra-human, and illuminist criteria, praising this procedure of creation which requires face and meaning to be parallel. Both groups have emphasized the unconsciousness of creation at the same time, but they have considered creativity to require fixed principles. Despite the fact that amateur teachers who focused more on creativity using spatial tools like computers have not considered creativity to require invariable principles, but they have not considered creation to happen without being inspired by an eternal source, i.e. the poetic inspiring force which is used by modern architecture teachers. 


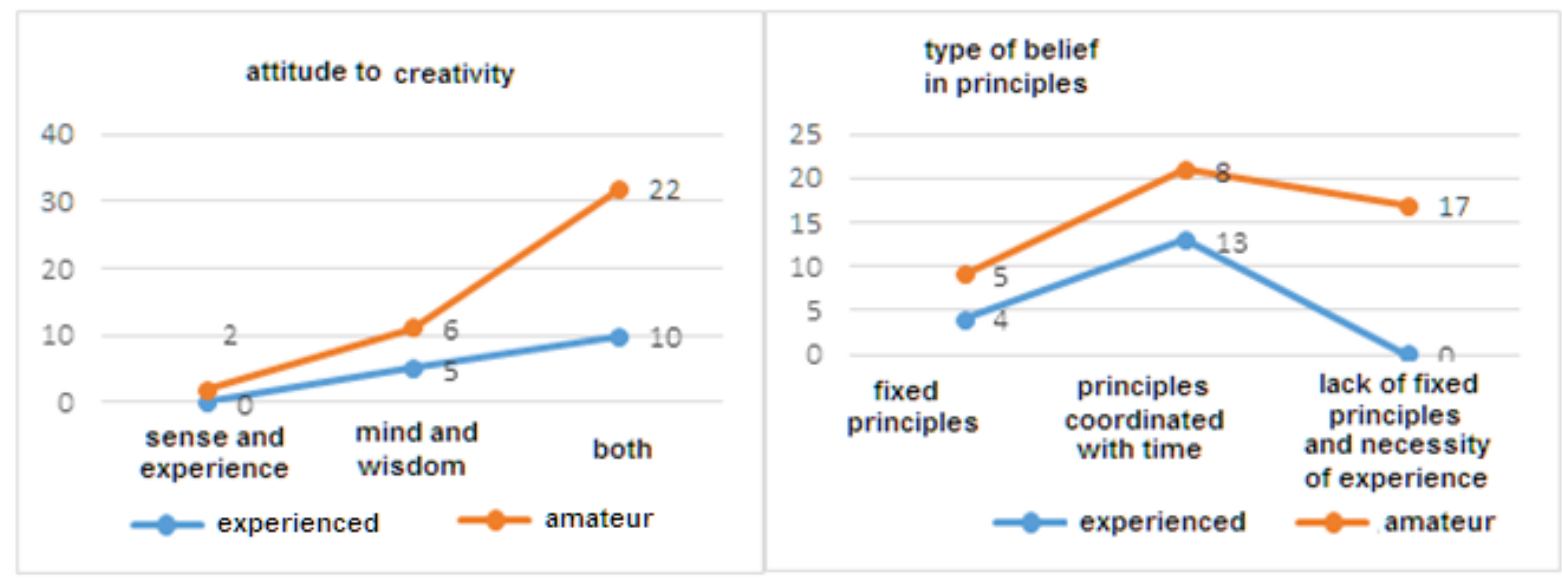

In the comparison of the comments presented by both experienced and inexperienced teachers in connection to principles in coordination with time, inexperienced teachers find it necessary to use experience, and experienced teachers, while believing more in invariable eternal principles, find it necessary to focus on principles in coordination with perfection time and the principle of timely understanding.
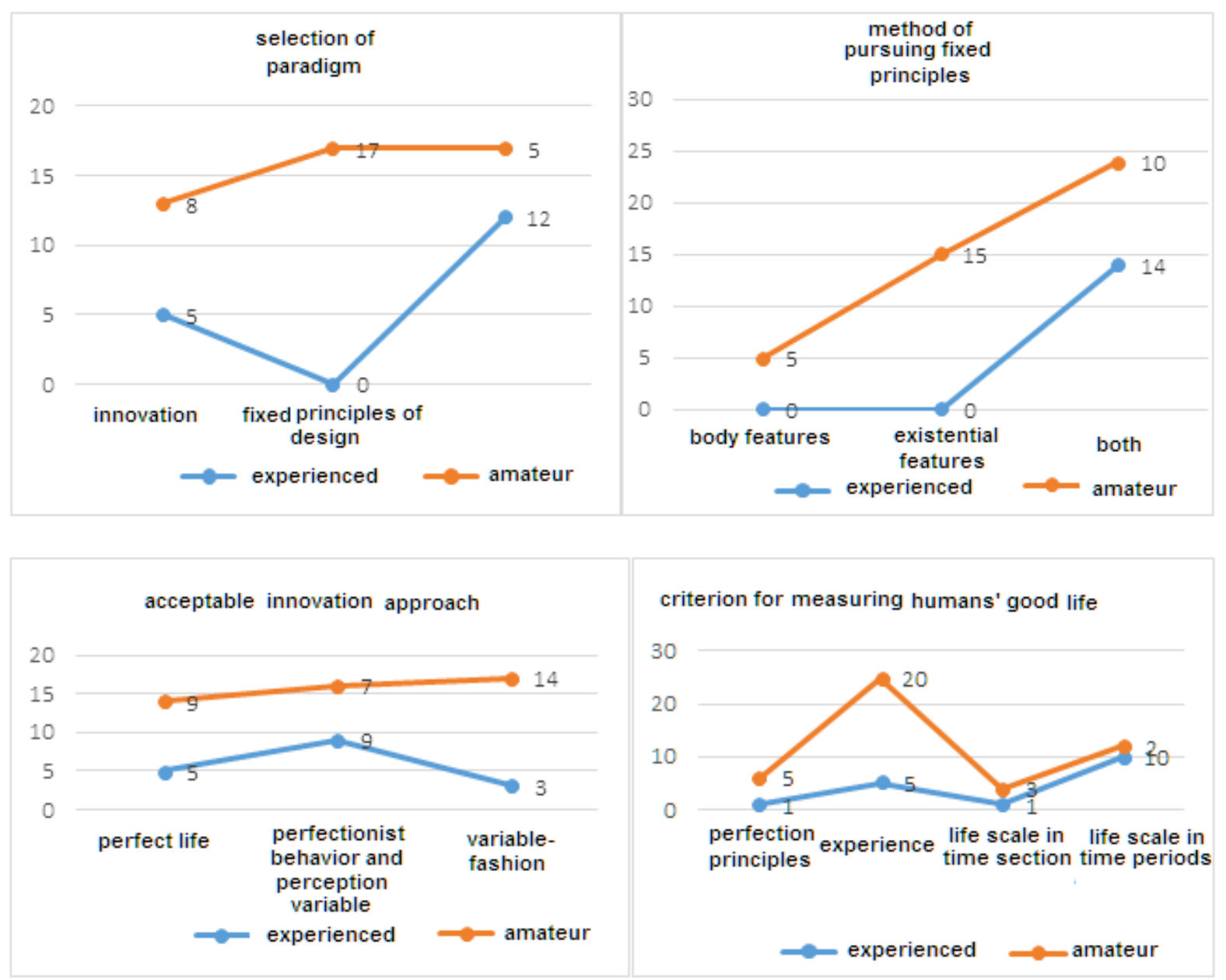

70 percent of teachers believing in fixed eternal principles leading to creativity do not consider creativity to mean happiness. In this outlook, they have emphasized the concurrence and similarity of face and meaning. They have considered facial beauty in real creativity taken from an eternal origin leading to a meaning which refers to humans' existential needs for architectural locations. In this outlook, space or object is created. Architecture is not looked at as a body. It is seen as an identity for 
humans. Innovative and intellectual masters emphasize life and health when focusing on space creation; they have accepted creativity not in existential meaning but more in terms of innovation according to personal natural and objective experiences; and they have considered this innovation to be prior to the acceptance of principles, without understanding and personal experience.

\section{CONCLUSION}

According to architecture definitions, there are common beliefs that architecture is meaningful from an existential viewpoint, but with different perceptions. From a traditional perspective, God's creation and real beauty requires reality and existence. Architecture is tied with wisdom and intellect in reality and God which are creativity and beauty. From a traditional viewpoint, an architect's art is not merely an individual and artistic work. In traditional architecture, unlike architectures taken from modernity, there is claimed to be an inherent relationship between beautiful face and meaning. Traditional civilizations in a texture of behavior and body, created group identity meaning in time; creativity is meaningful only in line with timely existence. Hence, such civilizations did not readily accepted rapid and new changes. Perfect identity relating to the spiritual world, is higher than humans' Temporal and materialistic intentions. Identity as humans' essence in the most perfect definition of human is tied with their meaningful structure and space creation. Identity definition of every individual in his living place; they are affected by what they create and they also affect their creations. Such an existential identity is created in their lifespan. In the perfect definition of creation, object creativity is not just referred to as beauty; but the meaning of beauty is not manifested in an ugly body.

Despite the fact that amateur teachers have emphasized the presence of fixed principles in the process of creativity, they have not introduced any criterion but personal experience for evaluating creative works. In students' projects, body innovation can be referred to as architecture formalism. What was related to age and life has been limited to a beautiful sculpture. In both methods, humans seek perfection and beauty. The result and fruit of this beauty lies in beautiful and perfect life. In this path, through intellectualism and perfectionism with intellect within creating a memorial of eternal location, paradise has focused on Garlic internal and external in order to provide an opportunity to move towards illumination by focusing on experiences and innovation. Both thinking creeds have taken steps to have self-knowledge and return to eternal identity. Face in time belongs to floating existence. Rapid changes without existential tests, frozen in a single face, and without timely understanding of humans were not accepted by the statistical population of the study; but creative change with timely existential test was emphasized.

It must be noted that as the face of tradition has been based upon meaning, face dogmatism without understanding the "timely" component will lead to lack of creativity.

\section{REFERENCES}

Awani, Gholamreza., (1375), "the origins of metaphysical art, wisdom and spiritual art", published by Gross, Tehran.

Akrami, Gholamreza., (1381), "Architecture, the first step tutorials, challenges and contradictions", Journal of Fine Arts, Issue 16, Ss33-48.

Eliade, Mircea, (1375), "The myth of eternal recurrence", translation Feb Srkaraty, second edition, published in diameter, Tehran.

Benevolo, Leonard (1384), "History of Modern Architecture", translation Cyrus believe, second printing, publishing, Tehran University, Tehran.

Pakbaz, Roein, (1367), "keeping up with the literature in Iranian painting" look Publications, Tehran.

Reed, Herbert (1374), "meaning art", translation Najaf Darya, Scientific and Cultural Publications, Tehran.

Shaw, George Bernard, (1950), "the words of Bernard Shaw", translation Abbas informant, no disappointments.

Schultz, Norberg. (1381). Architecture, attendance, time and location. (Reza Seyyed Ahmadi, Translator). Tehran: Lotus Publishing.

Guenon, Rene, (1349), "The crisis of the modern world", translation Zia Dehshiri, printing, publishing, Tehran University, Tehran. 
Guenon, Rene, (1365), "control quantity", translated by Ali Mohammad resourceful, University Publication Center, Tehran.

Nasr, Seyyed Hossein, (1393), "The need to Sacred Science", translated by Hussein Miandar, Third Edition, published by Taha, Tehran.

Nasr, Seyyed Hossein, (1389), "knowledge and spirituality", translation Ansha'a. Rahmati, Third Edition, published Suhrawardi, Tehran.

Heidegger, Martin. (1386). Being and Time. (Siavash Jamadi, Translator). Printing, Tehran: Phoenix Publishing. 